\title{
Guidelines for Clostridium difficile infection in adults
}

\author{
Michał Kukla ${ }^{1,2}$, Krystian Adrych $^{3}$, Agnieszka Dobrowolska ${ }^{4}$, Tomasz Mach ${ }^{5}$, Jarosław Reguła ${ }^{6,7}$, \\ Grażyna Rydzewska ${ }^{8,9}$ \\ ${ }^{1}$ Department of Internal Medicine and Geriatrics, Jagiellonian University Medical College, Krakow, Poland \\ ${ }^{2}$ Department of Endoscopy, University Hospital, Krakow, Poland \\ ${ }^{3}$ Department of Gastroenterology and Hepatology, Medical University of Gdansk, Gdansk, Poland \\ ${ }^{4}$ Department of Gastroenterology, Dietetics and Internal Diseases, Poznan University of Medical Sciences, Poznan, Poland \\ ${ }^{5}$ Department of Gastroenterology, Hepatology and Infectious Diseases, Jagiellonian University Medical College, Krakow, Poland \\ ${ }^{6}$ Department of Gastroenterology, Hepatology and Clinical Oncology, Medical Postgraduate Education Centre, Warsaw, Poland \\ 7Department of Gastrointestinal Oncology, "Maria Sklodowska-Curie" Clinical Oncology Institute, Warsaw, Poland \\ ${ }^{8}$ Central Clinical Hospital of Ministry of Inferior and Administration, Warsaw, Poland \\ ${ }^{9}$ Collegium Medicum, Jan Kochanowski University, Kielce, Poland
}

Gastroenterology Rev 2020; 15 (1): 1-21

DOI: https://doi.org/10.5114/pg.2020.93629

Key words: Clostridium difficile infection, pseudomembranous colitis, diarrhea, antibacterial treatment, fecal microbiota transplantation.

Address for correspondence: Prof. Michał Kukla, Department of Internal Medicine and Geriatrics, Jagiellonian University Medical College, 2 Jakubowskiego St, 30-688 Krakow, Poland, phone: +48 603388 086, e-mail: kuklamich@poczta.onet.pl

\begin{abstract}
Clostridium difficile infection (CDI) has become a serious medical and epidemiological problem, especially in well developed countries. There has been evident increase in incidence and severity of CDI. Prevention, proper diagnosis and effective treatment are necessary to reduce the risk for the patients, deplete the spreading of infection and diminish the probability of recurrent infection. Antibiotics are the fundamental treatment of CDI. In patients who had recurrent CDI fecal microbiota transplantation seems to be promising and efficient strategy. These guidelines systematize existing data and include recent changes implemented in the management of CDI.
\end{abstract}




\section{Guideline methodology}

The clinical practice guidelines for management of Clostridium difficile infections in adults were developed by the task force of the Board of the Polish Gastroenterology Society. This document summarises recommendations for improved diagnosis and treatment of $C$. difficile infections (CDI) in adults. The definition of CDI includes symptoms, usually diarrhoea, and a positive stool test for $C$. difficile toxin, or detection of a toxin-producing C. difficile strain, or a typical endoscopic image, or pathology study confirming pseudomembranous colitis. In addition, for proper diagnosis, treatment, patient care, and prevention, the guidelines include recommended methods of infection control, patient management, and infection prevention. The panel includes systematic rating of strength and quality of evidence in compliance with the GRADE system (evaluation of rating, recommendation development, and assessment) (Tables I and II). A detailed description of the methods, background, and summary of evidence in support of each recommendation is provided in the full text of the guidelines.

\subsection{Scope and aims of the guidelines}

\subsubsection{Aims}

Clostridium difficile is still the most common cause of healthcare-associated diarrhoea. It became the most

Table I. Strength of recommendation statement according to the GRADE rating system

\begin{tabular}{ll} 
Strength of recommendation statements \\
\hline Strong & $\begin{array}{l}\text { The benefits considerably outweigh the risks and } \\
\text { losses, or vice versa. Usually, the recommendation } \\
\text { statement is tagged 'recommended' }\end{array}$ \\
\hline Weak & $\begin{array}{l}\text { The benefits precisely balance the risks and losses. } \\
\text { Usually, the recommendation statement is tagged } \\
\text { 'suggested' }\end{array}$
\end{tabular}

important pathogen in hospitalised patients for several reasons. The main purpose of the guidelines is to identify the best methods for diagnosis and management, as well as the most effective, sufficient, and safe treatment regimens for $\mathrm{CDI}$ patients. We expect that application of the guidelines will translate into greater disease awareness, help reduce costs of differential diagnosis, and will contribute to appropriate CDI management.

\subsubsection{Health problems discussed in the guidelines}

The following CDI-associated health questions are covered in the guidelines:

1. What is the aetiology of CDI?

2. What has been the epidemiological situation of CDI in recent years?

3. What are the clinical symptoms of CDI?

4. What are the diagnostic criteria for CDI?

5. Which clinical tools should be considered in differentia diagnosis?

6. What is the proper management of CDI (including therapy, patient monitoring, isolation, and supportive care)?

\subsubsection{Target patient population of the guidelines}

The guidelines discuss management of adult patients (over 18 years of age) of both sexes with symptoms suggestive of CDI, with the diagnosis confirmed based on current criteria, regardless of the type or severity of symptoms. In addition, recommendations for managing CDI also include patients with recurrent infection.

\subsection{Development of recommendation statements}

The clinical practice guidelines are recommendation statements aimed at optimising patient care, based on the systematic review of evidence as well as evaluation of benefits and losses of alternative medical care [1].

Table II. Quality of evidence according to GRADE

\begin{tabular}{ll} 
Quality of evidence \\
\hline High & $\begin{array}{l}\text { One or more high-quality, well-constructed, randomised controlled trials (RCT) have provided consistent results for direct } \\
\text { implementation in clinical practice. It means that further research is unlikely to affect the expected outcomes }\end{array}$ \\
\hline Moderate & $\begin{array}{l}\text { Supported by RCTs but with significant limitations (i.e. biased assessment of therapeutic outcomes, high patient loss during } \\
\text { follow-up, no blinding, unexplained heterogeneity), indirect evidence from similar (but not identical) study populations, and } \\
\text { studies with very few patients or observed events (end-points). } \\
\text { In addition, there is some evidence from well-designed, non-randomised controlled trials, from well-constructed cohort or } \\
\text { case-control analytical studies, and from many case series with or without an intervention. } \\
\text { It means that further research can probably have an important impact on the expected outcomes and can change them }\end{array}$ \\
\hline $\begin{array}{l}\text { Observational studies, typically of low quality due to a risk of errors. This means that further research will almost certainly } \\
\text { have a significant impact on the expected outcomes and will most likely change them }\end{array}$ \\
$\begin{array}{l}\text { The evidence is contradictory, of low quality, or with no results; therefore, the balance of benefits and risks cannot be } \\
\text { determined. } \\
\text { It means that the expected outcomes are highly uncertain as evidence or are even unavailable or do not allow one to draw } \\
\text { any conclusions }\end{array}$
\end{tabular}


Table III. The agreement level of votes

\begin{tabular}{lc} 
Category & Agreement level \\
\hline A & Fully accepted \\
\hline B & Accepted with some objections \\
\hline C & Accepted with major objections \\
\hline D & Rejected with some objections \\
\hline E & Fully rejected
\end{tabular}

Categories A and B selected by $\geq 80 \%$ experts

Categories $A$ and $B$ selected by $<80 \%$ experts
High level of agreement between experts

Low level of agreement between experts
The practice guidelines were developed by a multidisciplinary panel of experts in epidemiology, diagnosis, infection control, and treatment of adult CDI patients. Only original studies (optimally prospective, randomised, double-blinded, placebo-controlled studies) were incorporated for the development of the guidelines. In the absence of such studies, the evidence of lower quality was considered, including observational and retrospective studies (excluding case series and case reports), as well as systematic reviews and meta-analyses. The source data were found in the following electronic databases: PubMed, NCBI, Cochrane Library, Researchgate, and GoogleScholar, as well as in the recommendation statements and guidelines published on the websites of international scientific societies. The literature review and analysis were limited to articles published in either English or Polish.

The evaluation of the quality of evidence and the strength of recommendation statements was supported by the Grading of Recommendations Assessment, Development, and Evaluation system (GRADE) (Tables I and II). Delphi voting was implemented for the final decision making. The acceptance level for each rec- ommendation statement was assessed by the expert panel on a five-point scale (A-E) and determined by the agreement level (Table III). Each recommendation statement was discussed taking into consideration the scientific evidence used for its formulation, covering the relationship between the guidelines and the scientific data. Based on the acceptance level, the consensus between experts was considered high when $80 \%$ or more of voters chose $A$ or $B$ categories. When the results were below $80 \%$, the agreement level was deemed low.

\subsubsection{Recommendation statement interpretation}

The graphic interpretation scheme is shown below. Each recommendation statement consists of three parts regarding its strength, the quality of evidence, and the distribution of the expert votes.

- The strength of the recommendation statement is considered strong or weak according to the GRADE rating system.

- The quality of the evidence is considered high moderate, low or very low according to the GRADE rating system.

- The acceptance level by experts (rating scale

\section{Example}

\subsection{Recommendation statement 10}

\section{Private rooms and/or dedicated toilets for isolated CDI patients}

We recommend isolation for CDI patients, i.e. accommodation in private rooms with a separate toilet prevents infection transmission to other patients. When there are not enough toilets or single rooms, priority should be given to patients with stool incontinence, who should be placed in single rooms.

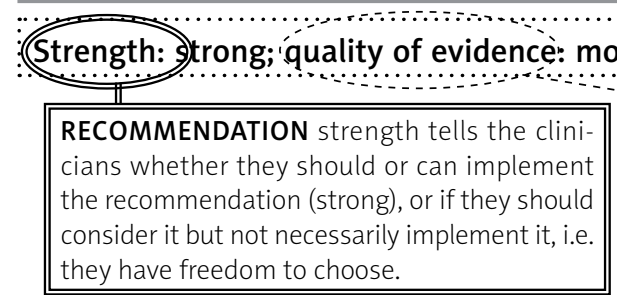

\section{Voting}

$A-\% ; B-\% ; C-\% ; D-\% ; E-\% \leftarrow$ percentage of experts in favour of the recommendation statement.

Agreement level: $\leftarrow$ When $\geq 80 \%$ chose category $A$ or $B$, the agreement level was high; otherwise it was low. 


\section{Epidemiology}

\subsection{Recommendation 1}

\section{Recommended definition of CDI}

To monitor infection sites and to increase comparability between analyses, the widely available standard definitions of primary infection should be used, including: (1) healthcare-onset (HO) CDI - the site of primary infection is in a healthcare facility, e.g. hospital; (2) community-onset, healthcare facility-associated (CO-HCFA) CDI - infection occurring in a non-hospital environment following contact with healthcare facilities; and (3) community-associated (CA) CDI infection with no relation to a hospital stay.

(Good practice recommendation)

Voting:

A - 83.3\%; B - 16.7\%; C - 0\%; D - 0\%; E - 0\%.

Agreement level: $\mathrm{HIGH}$.

\subsection{Recommendation 2}

Recommendation on minimal supervision for institutions with limited resources

Implement HO-CDI surveillance in all hospitals to identify increased risk or outbreaks of CDI in the healthcare facility.

(Recommendation: weak; quality of evidence: low) Voting:

A - 50\%; B - 33.3\%; C - 16.7\%; D - 0\%; E-0\%.

Agreement level: HIGH.

\subsection{Recommendation 3}

Recommendation on the best way to express CDI incidence and prevalence

Express $\mathrm{HO}-\mathrm{CDI}$ prevalence as the number of cases per 10,000 man-days of treatment. Express CO-HCFA prevalence as the number of cases per 1000 patient admissions.

(Good practice recommendation)

Voting:

$A-83.3 \%$; $B-16.7 \%$; $-0 \%$; D - 0\%; $E-0 \%$.

Agreement level: $\mathrm{HIGH}$.

\subsection{1./2.2.1./2.3.1. Discussion}

Clostridium difficile infection is a major cause of antibiotic-associated diarrhoea. It is responsible for $15-25 \%$ of all cases, with a considerable increase in the number of CDI cases in the $21^{\text {st }}$ century [2]. In 2016 a report was issued evaluating 7711 CDI cases from 20 countries. The number of healthcare-associated (HA) CDI cases was 5756 (74.6\%), and the number of community-associated (CA) CDI cases was 1955 (25.4\%). In the hospital, from which the analysed data were obtained, men constituted $44.9 \%$ of patients, with the average age of 75.0 years. The incidence of HA CDI was 2.4 cases/10,000 man-days. As for 126/593 (21.2\%) of the hospital surveillance period, no cases of HA CDI were observed. The median in-hospital incidence of HA CDI was 2.9 cases per 10,000 man-days. The average incidence of CDI was the highest in reference hospitals ( 5.8 cases $/ 10,000$ man-days; $95 \%$ Cl 3.6-7.8 cases/10,000 man-days). It was also the lowest in community hospitals (2.8 cases/10,000 man-days; $95 \% \mathrm{Cl}$ : 2.1-3.5 cases $/ 10,000$ man-days; $p=0.001)$. Estonia, Lithuania, and Poland reported the highest incidence of HA CDI.

The incidence of CA CDI was 0.8 cases/10,000 mandays, with the highest rates being reported by Estonia, France, and Poland [3].

Clostridium difficile is a Gram-positive, obligate anaerobe and a spore-forming bacterium, which was first identified in 1935 [4]. The most common route of transmission is faecal-oral. At the beginning of the $21^{\text {st }}$ century, an increase in CDI incidence was observed due to the rapidly spreading NAP1 strain (North American Pulse Field Type 1) otherwise known as ribotype 027 or B1/NAP1/027. This strain caused both an increased risk of developing hospital-based endemic foci and a regional increase in CDI incidence. The endemic strain B1/NAP1/027 is hypervirulent, characterised by an increased ability to form spores, high resistance to fluoroquinolones, and it more often causes infections with severe clinical course $[5,6]$.

Over the last decade, one of the most serious epidemiological problems was the increase in C. difficile infection rate in hospitals. Based on Kronika Epidemiologiczna (pol. the epidemiological chronicle), in 2016 C. difficile infections accounted for $28.3 \%$ of all registered outbreaks of hospital-acquired infections. There were 8716 cases reported, of which 540 were fatal [7].

According to the data from the National Institute of Public Health - National Institute of Hygiene in Poland, in 2017 the incidence of CDI was 30.2 per 100,000 inhabitants. There were 11,667 reported cases. Hospital stay was required in $88.1 \%$ of patients [8]. In the years 2011 to 2013 , clinical studies were conducted in 13 hospitals in Poland, proving that PCR ribotype 027 CDIs predominate $(62 \%)$. The second most common aetiological factor is ribotype 176 , responsible for $14 \%$ of CDIs [6].

\section{Risk factors of CDI}

CDI infections are significantly more common in patients with risk factors, including: antibiotic therapy, age over 65 years, hospitalisation for more than 4 weeks or stay in a long-term medical care facility, comorbidities, diseases associated with immunosuppression or che- 
Table IV. Antibiotics and the risk of CDI

\begin{tabular}{ccc} 
High risk & Moderate risk & Low risk \\
\hline Fluoroquinolones & Macrolides & Aminoglycosides \\
$2^{\text {nd }}$ and $3^{\text {rd }}$ generation cephalosporins & Trimethoprim/sulfamethoxazole & Metronidazole \\
Clindamycin & Other penicillins & Teicoplanin \\
Ampicillin & Sulphonamides & Vancomycin \\
Broad-spectrum penicillins with inhibitors & & Rifampicin \\
(except for ticarcillin with clavulanate and & Chloramphenicol \\
piperacillin with tazobactam) & Tetracycline \\
& & Carbapenems \\
& Daptomycin & Tigecycline
\end{tabular}

motherapy, and use of proton pump inhibitors. Chronic diseases that promote CDI infection include: chronic kidney disease, dialysis, cystic fibrosis, diabetes, stroke, malnutrition, alcoholism, chronic heart disease, chronic lung disease, primary and secondary immunity disorders - including HIV, cancer, and non-specific inflammatory bowel diseases [4]. Almost every antibiotic used can be a risk factor for the development of CDI; even the drugs used to treat CDI - vancomycin and metronidazole - are a risk factor for the disease. Antibiotics were divided into three groups, depending on the degree of risk of CDI induction (Table IV) [5].

\section{Clostridium difficile colonisation and infection}

Clostridium difficile transmission in a healthcare facility is most likely the result of faecal-oral spread or direct contact with a contaminated environment. The asymptomatic colonisation rate with $C$. difficile is 3-26\% among adult in-patients. The rate of asymptomatic $C$. difficile presence in stool in adults is $<2 \%$. Research suggests that individuals with asymptomatic colonisation for a prolonged time have a reduced risk of developing CDI. Long-term colonisation may be dependent on the increase of anti-A and anti-B toxin serum antibodies [9].

The main routes of $C$. difficile transmission include: hands of the medical staff and a polluted environment, an inadequately cleaned room previously occupied by a CDI patient, and contaminated thermometers and other medical equipment.

Different forms of CDI are summarised in Table $\mathrm{V}$ [10-12].

\subsection{Recommendation 4}

Recommendation on CDI surveillance in the face of high endemic or epidemic rates

Classify data based on patient location in order for appropriate control measures when CDI incidence exceeds average rates and/or it is impossible to limit the disease spread, or an outbreak occurs.

(Recommendation: weak; quality of evidence: low) Voting:

A - 83.3\%; B - 16.7\%; C - 0\%; D - 0\%; E- 0\%.

Acceptance level: $\mathrm{HIGH}$.

Table V. Severity of CDI

\begin{tabular}{|c|c|c|c|}
\hline Severity & SHEA and IDSA criteria [10] & $\begin{array}{l}\text { Criteria by } \\
\text { Zar et al. [11] }\end{array}$ & $\begin{array}{l}\text { Criteria accepted by the National } \\
\text { Program for Antibiotic Protection } \\
\text { according to McDonald et al. [12] }\end{array}$ \\
\hline Severe & $\begin{array}{c}\text { Leukocytosis } \\
\geq 15,000 / \mathrm{mm}^{3} \\
\text { and } / \text { or }\end{array}$ & $\begin{array}{l}\quad \text { At least } 2 \text { of the following: } \\
\text { - age } \geq 60 \\
\text { - temperature } \geq 38.3^{\circ} \mathrm{C} \\
\text { - albumin } \leq 2.5 \mathrm{~g} \% \\
\text { - leukocytosis } \geq 15000 / \mathrm{mm}^{3} \\
\text { and/or } \\
\text { - pseudomembranes on endoscopy } \\
\text { and/or } \\
\text { - treatment in ICU }\end{array}$ & $\begin{array}{l}\text { Within } 30 \text { days since CDI diagnosis: } \\
\text { - treatment in ICU due to } \\
\text { complications (e.g. shock, } \\
\text { catecholamine infusion) or } \\
\text { - surgery due to complications (toxic } \\
\text { megacolon, perforation, ineffective } \\
\text { medical treatment) }\end{array}$ \\
\hline Fulminant & Leukocytosis $>50,000 / \mathrm{mm}^{3}$ & - & - \\
\hline $\begin{array}{l}\text { Severe } \\
\text { complicated }\end{array}$ & Ileus, perforation, or shock & - & $\begin{array}{l}\text { Toxic megacolon, perforation, } \\
\text { ineffective medical treatment, or death }\end{array}$ \\
\hline
\end{tabular}




\subsubsection{Discussion}

Special supervision is required in patients with diarrhoea, toxic megacolon, or severe ileus [13], as well as in those testing positive or with pseudomembranes on endoscopy or microscopy. The occasional infection is a new first episode of symptoms, i.e. no symptoms were present within the preceding 8 weeks; positive test result - enzyme-linked immunosorbent assay (EIA) or nucleic acid amplification assay (NAAT). The current infection is the onset of symptoms and a positive stool test following an episode, with a positive test result within the previous 2 to 8 weeks [14].

Surveillance of specific communities in the event of an outbreak in non-hospitalised individuals should be considered to determine the incidence trends in the given population. Adequate classification of patients by place of residence can improve infection control.

\section{Symptoms, differential diagnosis, and diagnostic criteria}

\subsection{Recommendation 5}

Preferred patient population for testing, most sus-
pected of CDI
Patients with new, unexplained diarrhoea with $\geq 3$
loose stools within $24 \mathrm{~h}$ are the preferred target pop-
ulation for CDI testing.
(Recommendation: weak; quality of evidence: very
low)
Voting:
A - $50 \%$; B - 50\%; C-0\%; D-0\%; E-0\%.
Acceptance level: $\mathrm{HIGH}$.

\subsubsection{Discussion}

Testing for $C$. difficile infection should include individuals with an unexplained new episode of three or more loose stools within $24 \mathrm{~h}$. The optimal number of loose stools required for $C D I$ testing depends on the likelihood of infection (high vs. low) and potential confounding factors such as an underlying disease and surgical interventions. Potential confounding factors may contribute to an increased risk of antibiotic-associated diarrhoea. When a patient presents with diarrhoea that cannot be attributed to any disorder, testing for $C$. difficile infection is recommended. Testing should also be conducted when diarrhoea persists despite discontinuation of treatment, e.g. with laxatives.

Some conditions and medical interventions relating to the diarrhoea itself, such as irritable bowel syndrome (IBS) or enteral feeding, are associated with an increased risk of CDI. In clinical practice, it is difficult to exclude CDI in patients with new-onset or severe diarrhoea. The clinical criteria for the diagnosis of CDI have changed along with increasing awareness of $C$. dif- ficile infection. It is worth mentioning that the number and frequency of loose stools justifying CDI testing have decreased over the last 40 years. In 1974, Tedesco et al. defined diarrhoea as $>5$ stools a day [15]. In 2013, Johnson et al. defined diarrhoea as $>3$ loose stools or watery bowel movements within $24 \mathrm{~h} \mathrm{[16].} \mathrm{Clinicians}$ can improve the test accuracy only by examining patients suspected of $C$. difficile infection.

\subsection{Recommendation 6}

The most effective methods (in terms of positive and negative predictive values) to identify patients at risk of a clinically significant $C$. difficile infection based on stool testing

Use a stool toxin test as part of a multi-step algorithm, i.e. 1. glutamate dehydrogenase (GDH) and toxin; 2. GDH plus toxin, confirmed by nucleic acid amplification test (NAAT); or 3. NAAT plus toxin. This algorithm is recommended rather than NAAT alone for all samples sent to the laboratory when there are no local guidelines for stool sampling.

(Recommendation: weak; quality of evidence: low) Voting:

A - 66.6\%; B - 16.7\%; C - 16.7\%; D - 0\%; E - 0\%. Acceptance level: $\mathrm{HIGH}$.

\subsubsection{Discussion}

Clostridium difficile infection should be suspected in patients with diarrhoea ( $\geq 3$ loose stools within $24 \mathrm{~h}$ ) of unexplained origin. Many laboratory studies can be implemented in CDI diagnosis. Those methods are based on direct detection of bacteria as well as one or both major toxins (A and B) in stool. Table I lists those methods in order of decreasing analytical sensitivity. Toxicological cultures include selective medium or its variant and anaerobic incubation for several days. Later the organism is identified using several methods such as laser desorption, matrix-assisted ionisation mass spectrometry. The characteristic 'horse barn' smell often heralds the presence of $C$. difficile. After pathogen identification, testing for toxins should be performed to confirm infection with the toxin-producing strain. Toxicological culture is one of the gold standard methods, to which other studies are compared.

Another reference method is a cell culture cytotoxicity neutralisation assay (CCNA) [17]. It allows for direct detection of toxins in stool. First, stool filtrate is prepared and administered to an appropriate monolayer cell line such as Vero cells or human fibroblasts. After incubation, the cells are observed for cytopathic effect (CPE). The control study is carried out simultaneously using neutralising antibodies to Clostridium sordellii or C. difficile to confirm that CPE is caused by the toxins 
Table VI. Available tests for CDI detection in order of decreasing sensitivity [1]

\begin{tabular}{lccc}
\hline Test & Sensitivity & Specificity & Detected substance \\
\hline Bacterial cultures & High & Low* & C. difficile vegetative forms or spores \\
\hline Nucleic acid amplification test & High & Low/moderate & C. difficile nucleic acid (toxin genes) \\
\hline Glutamate dehydrogenase & High & Low* & C. difficile common antigen \\
\hline $\begin{array}{l}\text { Cytotoxicity neutralisation test } \\
\text { on a cell culture }\end{array}$ & High & High & Free toxins \\
\hline $\begin{array}{l}\text { Immunological tests detecting } \\
\text { toxins A and B }\end{array}$ & Low & Moderate & Free toxins \\
*The test should be accompanied by toxin detection methods. & &
\end{tabular}

produced by $C$. difficile and not by other substances in the stool. Incubation is continued for a maximum of $48 \mathrm{~h}$, but positive results can often be obtained after overnight incubation. This method is time-consuming and lacks standardisation; however, it is characterised by high sensitivity and specificity. CCNA has been supplanted by faster antigen and molecular testing methods. Enzyme immunoassays (EIAs) detect proteins in the tested material using monoclonal or polyclonal antibodies linked to an enzyme. At first, the tests only detected toxin $A$; however, with time both toxins $A$ and $B$ started to be detected. Toxins $A$ and $B$ and hydrolytic enzymes including hyaluronidase, chondroitin sulfatase, gelatinase, and collagenase are virulence factors of $C$. difficile. Toxin $A$ is an enterotoxin stimulating production of cytokines, chemokines, and substance P. In addition, toxin A stimulates neutrophil dipeptidase production in the intestinal lumen, leading to disruption of connections between enterocytes and their apoptosis. Toxin B is a cytotoxin causing apoptosis of enterocytes damaged by toxin A. Both toxin A and toxin B inactivate Rho GTPase (guanosine triphosphate hydrolase) leading to depolymerisation of actin fibres and damage to the skeleton of the colon epithelial cells, resulting in pseudomembrane formation. They consist of neutrophils, fibrin, mucus, and enterocyte residues. Microscopically, pseudo-membranes form of yellowish-white deposits on the inflamed colonic mucosa.

The most frequently used method in CDI diagnosis is based on direct detection of $C$. difficile toxin in a stool sample. In selected patients, e.g. with inflammatory bowel disease, it is recommended that CDI be tested for at every disease exacerbation. The most commonly used method is the enzyme immunoassay (EIA) $[17,18]$, which gives quick results, i.e. after $1-2 \mathrm{~h}$. The sensitivity is $75-85 \%$ and specificity $95-100 \%$. EIAs use monoclonal or polyclonal antibodies to detect $C$. difficile toxins, and many commercial tests are available. Due to poor performance of EIA tests, GDH (glutathione dehydrogenase) immunoassays and molecular tests for detecting toxin genes have been developed [19, 20]. Glutamate dehydrogenase immunoassays detect the metabolic enzymes present in all C. difficile isolates. The antigen detected by the GDH test is not specific only to $C$. difficile toxin-producing strains, it is also present in non-toxin-producing $C$. difficile bacteria. The combination of two tests allows for a faster result and better sensitivity compared to the EIA tests alone [20]. In 2009, the nucleic acid amplification test (NAAT) was used to detect CDI. The test is based on the PCR (polymerase chain reaction) method and has a higher sensitivity (80$100 \%$ ) and specificity (87-99\%) compared to the EIA test. The NAAT test has limitations in the form of high costs of implementation and difficulties in interpretation.

Table VI shows the available tests for CDI detection in order of decreasing sensitivity.

The optimal diagnostic method for CDI is hard to achieve.

Patients may also be carriers of toxin-producing strains without clinically apparent disease. Diarrhoea in hospitalised patients is common, and $C$. difficile is responsible for less than $30 \%$ of cases. Based on current understanding, it is difficult to indicate which method is the most useful in CDI detection. Tables VII and VIII compare the available diagnostic tests for CDI [21-27]. 
Table VII. Evidence for the recommended diagnostic tools for $C$. difficile infection diagnosis

\begin{tabular}{|c|c|c|c|c|c|}
\hline Evidence for diagnostic tools & Design & $\begin{array}{l}\text { Number of } \\
\text { participants }\end{array}$ & Limitations & $\begin{array}{l}\text { Quality of evidence } \\
\text { (GRADE) }\end{array}$ & $\begin{array}{l}\text { References, } \\
\text { first author }\end{array}$ \\
\hline $\begin{array}{l}\text { GDH and NAATs have the } \\
\text { highest sensitivity, but low PPV } \\
\text { in asymptomatic patients; all } \\
\text { tests had high NPV regardless of } \\
\text { symptoms }\end{array}$ & $\begin{array}{l}\text { Observational study, } \\
\text { patient interview } \\
\text { and clinical } \\
\text { assessment }\end{array}$ & 150 & $\begin{array}{l}\text { Low number of } \\
\text { participants; only } \\
\text { basic lab tests were } \\
\text { assessed in real time }\end{array}$ & & Dubberke [21] \\
\hline $\begin{array}{l}\text { Toxins - negative, NAAT - positive, } \\
\text { untreated patients showed no side } \\
\text { effects. The CDI relapse was more } \\
\text { common when both NAAT and } \\
\text { toxins were positive rather than } \\
\text { when only NAAT was positive ( } 31 \% \\
\text { vs. } 14 \% ; p=0.03 \text { ) }\end{array}$ & $\begin{array}{c}\text { Retrospective } \\
\text { observational study }\end{array}$ & 128 & $\begin{array}{l}\text { Low number of } \\
\text { participants }\end{array}$ & & Kaltsas [22] \\
\hline $\begin{array}{l}\text { No difference in positive } \\
\text { evaluation for EIA toxicity between } \\
\text { patients with mild and severe } \\
\text { disease ( } 49 \% \text { vs. } 58 \% ; p=0.31 \text { ) }\end{array}$ & $\begin{array}{l}\text { Observational } \\
\text { study, prospective } \\
\text { study, retrospective } \\
\text { assessment of } \\
\text { patient data }\end{array}$ & 299 & Single-centre study & & Humphries [23] \\
\hline $\begin{array}{l}\text { Complications were more common } \\
\text { with positive NAAT and GDH/EIA/ } \\
\text { CCNA compared to isolated positive } \\
\text { NAAT ( } 39 \% \text { vs. } 3 \% ; p<0.001)\end{array}$ & $\begin{array}{l}\text { Prospective cohort } \\
\text { study; observational }\end{array}$ & 1321 & $\begin{array}{l}\text { Only some samples } \\
\text { were tested using } \\
\text { the gold standard }\end{array}$ & & Longtin [24] \\
\hline $\begin{array}{l}\text { Patients with positive CCNA or } \\
\text { GDH/EIA showed higher all-cause } \\
\text { mortality compared to patients } \\
\text { with positive NAAT or TC }(p=0.001)\end{array}$ & $\begin{array}{c}\text { Multi-centred } \\
\text { observational study }\end{array}$ & 12420 & Limited clinical data & & Planche [25] \\
\hline $\begin{array}{l}\text { Patients testing positive for toxins } \\
\text { with EIA showed longer duration } \\
\text { of diarrhoea, more CDI-related } \\
\text { complications, greater CDI-related } \\
\text { mortality compared to patients } \\
\text { testing negative for toxins but } \\
\text { with positive PCR test result } \\
(8.4 \% \text { vs. } 0.6 \%, p=0.001)\end{array}$ & $\begin{array}{c}\text { Prospective } \\
\text { single-centre trial, } \\
\text { observational, } \\
\text { cohort }\end{array}$ & 1416 & Single-centre study & & Polage [26] \\
\hline
\end{tabular}

Table VIII. Evidence for recommended diagnostic tests for CDI. It is preferred to use NAAT alone or as a part of a multi-step algorithm (i.e. GDH plus toxin supported by NAAT or NAAT plus toxin) rather than testing for toxins when there are established institutional procedures for stool sampling

\begin{tabular}{|c|c|c|c|c|}
\hline $\begin{array}{l}\text { Evidence for diagnostic } \\
\text { tests }\end{array}$ & Study & $\begin{array}{l}\text { Number of } \\
\text { participants }\end{array}$ & $\begin{array}{c}\text { Quality of } \\
\text { evidence (GRADE) }\end{array}$ & $\begin{array}{l}\text { References, } \\
\text { first author }\end{array}$ \\
\hline $\begin{array}{l}\text { PCR was more sensitive } \\
(93.3 \%) \text { than EIA ( } 73.3 \%) \\
\text { for toxin detection and } \\
\text { direct cytotoxicity test } \\
(76.7 \%), \text { when used in } \\
\text { patients meeting clinical } \\
\text { criteria for CDI }\end{array}$ & $\begin{array}{l}\text { Observational; } \\
\text { patient interviews }\end{array}$ & 350 & & Peterson [27] \\
\hline $\begin{array}{l}\text { Using clinical diagnosis } \\
\text { as reference, PCR was } \\
\text { more sensitive than CCNA } \\
\text { and GDH ( } 99.1 \% \text { vs. } 51 \% \\
83.8 \% \text { ). Clinically confirmed } \\
\text { in } 91.5 \% \text { of cases }\end{array}$ & $\begin{array}{l}\text { Prospective double- } \\
\text { centre study }\end{array}$ & 1051 & $\begin{array}{l}\text { Various order } \\
\text { of tests; limited } \\
\text { statistical analysis; } \\
\text { limited patient } \\
\text { observation }\end{array}$ & $\begin{array}{l}\text { Berry N, Sewell B, Jafri S, } \\
\text { et al. Real-time polymerase } \\
\text { chain reaction correlates } \\
\text { well with clinical diagnosis of } \\
\text { Clostridium difficile infection. } \\
\text { J Hosp Infect 2014; 87: 109-14 }\end{array}$ \\
\hline
\end{tabular}



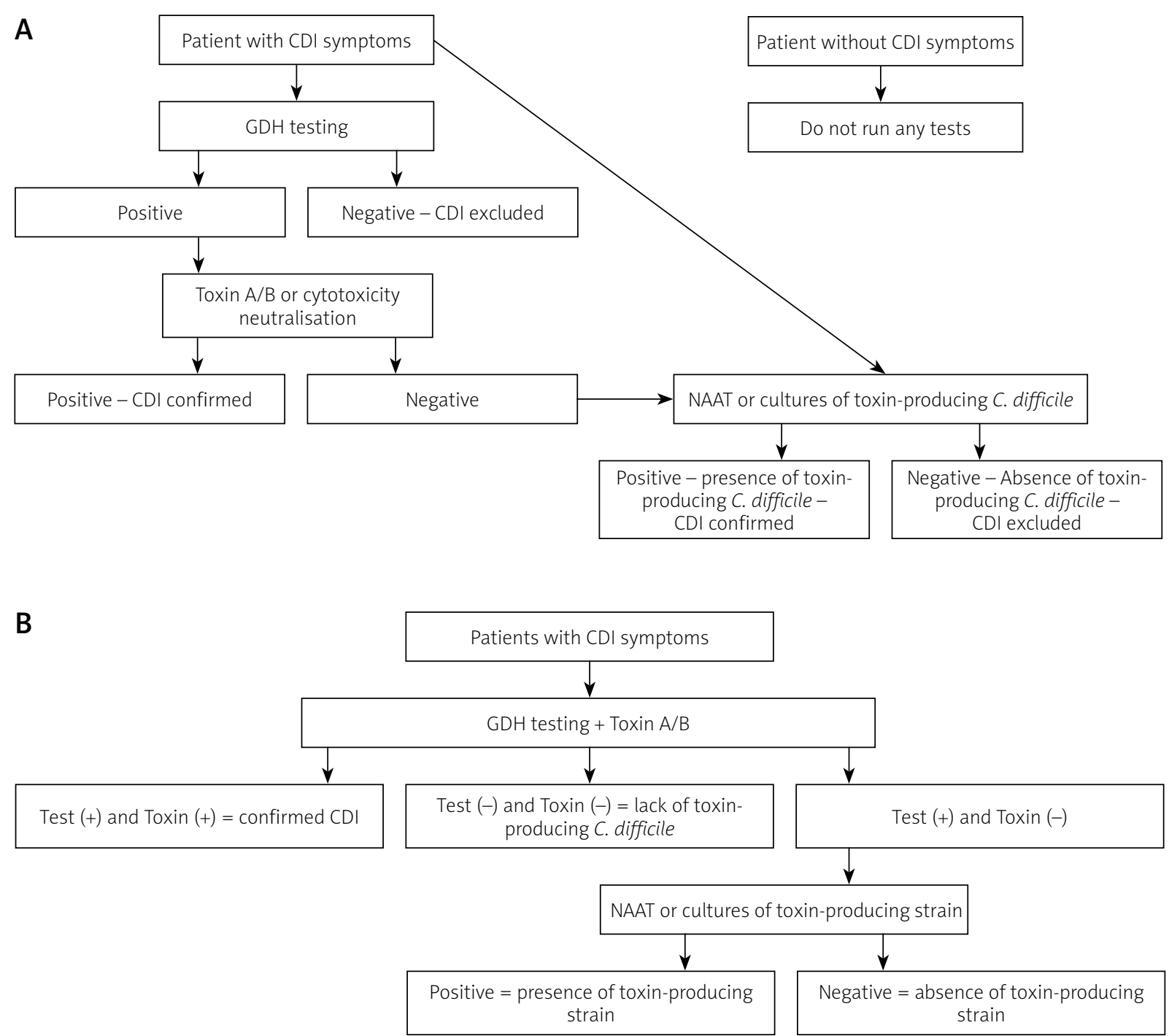

Figure 1. Recommended diagnostic algorithms for $C$. difficile infection $G D H$ - glutamate dehydrogenase, NAAT - nucleic acid amplification test, $C D I-C$. difficile infection.

\subsection{Recommendation 7}

The most sensitive method of CDI diagnosis in
stool in patients at risk of CDI based on clinical
presentation
If stool samples were obtained from patients who
were at risk of CDI based on clinical presentation,
use NAAT or a multi-step algorithm to test: 1 . GDH
plus toxin; 2 . GDH plus toxin and NAAT; and 3. NAAT
plus toxin. Those methods are preferred over toxin
detection itself, when there are established institu-
tional criteria for stool sampling.
(Recommendation: weak; quality of evidence: low)
Voting:
A-0\%; B - 100\%; C-0\%; D - 0\%; E- $0 \%$.
Acceptance level: HIGH.

\subsubsection{Discussion}

If patients are carefully examined for clinical symptoms of CDI (at least three loose stools within $24 \mathrm{~h}$, with a history of exposure to antibiotics), then the best way of further evaluation is a multi-step clinical algorithm. GDH plus toxin or GDH plus toxin/NAAT or NAAT plus toxin. A two- or three-step algorithm has greater diagnostic accuracy compared to single-step testing. Recommended diagnostic algorithms are shown on Figure 1. 


\subsection{Recommendation 8}

The role of repeated testing. Should repeated testing be considered in asymptomatic patients, including post-treatment control test?

During the same episode of diarrhoea, stool tests should not be repeated for 7 days. Stool testing should be avoided in asymptomatic patients. Stool testing can be performed for epidemiological studies in asymptomatic patients.

(Recommendation: strong; quality of evidence: moderate)

Voting:

$A-83.3 \%$; $B-16.7 \%$; $-0 \%$; D - 0\%; E - 0\%.

Acceptance level: HIGH.

\subsubsection{Discussion}

The issue of retesting for $C D I$ is strictly linked to the accuracy of the testing method. The use of suboptimal specificity tests means that multiple repetitions are associated with a high risk of false positives. In the absence of CDI suspicion, do not re-test. The use of highly sensitive testing strategies (two-stage or three-stage algorithms) means that individual tests have a very high negative predictive value (usually $>99 \%$ ).

\subsection{Recommendation 9}

The use of lactoferrin or other biological markers in stool to increase efficacy of CDI diagnosis compared to detecting toxin-producing $C$-difficile strains

There is insufficient evidence to recommend using biological markers to enhance diagnosis.

(No recommendation)

Voting:

A - 100\%; B - 0\%; C - 0\%; D - 0\%; E-0\%.

Acceptance level: $\mathrm{HIGH}$.

\subsubsection{Discussion}

In the recent years, there has been an increase in the number of biomarkers detected in stool used to differentiate inflammatory and non-inflammatory diarrhoea. Those include lactoferrin, calprotectin, as well as IL-8 and IL-1 $\beta$ [28].

Lactoferrin is an iron-binding glycoprotein found in neutrophils, and its concentration in the stool is proportional to the neutrophil count in stool [29]. Calprotectin is a calcium-binding protein found in the neutrophil cytosol [30, 31]. Secretion of intestinal cytokines such as IL-8 and IL- $1 \beta$ was also evaluated. Although the markers are used in the diagnosis of irritable bowel syndrome, their usefulness in the diagnosis of CDI has not been established [32].

\section{Infection control and prevention}

\subsection{Recommendation 10}

\section{Isolation of CDI patients}

Should separate rooms and toilets be used for isolated CDI patients?

Isolation recommendations for patients with CDI placing patients in separate rooms with separate toilets protects against disease transmission to other patients. When there are not enough toilets and single rooms, priority should be given to patients with stool incontinence, who should be placed in separate rooms.

(Recommendation: strong; quality of evidence: moderate)

Voting:

A - 100\%; B - 0\%; C - 0\%; D - 0\%; E - 0\%.

Acceptance level: $\mathrm{HIGH}$.

\subsubsection{Discussion}

Patients with confirmed or suspected CDI should be isolated. This is a preventive measure against infection spread in the ward. Additional precautions are often implemented, especially when CDI rates are high. The 'control packet' strategy for infection control is used to effectively control major CDI foci. It includes hand washing, isolation, environmental decontamination, and antibiotics [33-35]. The basis for CDI prevention and control are properly designed hospital rooms and hand washing products. Single rooms with private toilets are preferred. The effect of single rooms on CDI and other bacterial transmission rates was investigated when the ICU of one of the hospitals was closed for renovation [36]. It was established that the CDI rate decreased by $43 \%$. When patient grouping is necessary due to a lack of single rooms, the patients should be given individual lockers for storing private items, which reduces transmission.

\subsection{Recommendation 11}

Recommendations for cohorting infected or colonised patients with the same pathogen

If cohorting is necessary, it is recommended to group patients colonised or infected with the same pathogen. CDI patients should not be grouped if there is discordance with respect to other drug-resistant pathogens such as MRSA - methicillin-resistant Staphylococcus aureus or vancomycin-resistant Enterococcus.

(Recommendation: strong; quality of evidence: moderate)

Voting: A - 83.3\%; B - 16.7\%; C - 0\%; D - 0\%; E - 0\%. Acceptance level: $\mathrm{HIGH}$. 


\subsubsection{Discussion}

If patient cohorting is necessary, patients infected or colonised with the same pathogen should be grouped together. Patients with other drug-resistant pathogens such as MRSA or vancomycin-resistant Enterococci (VRE) should not be grouped together.

\subsection{Recommendation 12}

Should hospital staff wear gloves and gowns when caring for CDI patients?

Hospital staff should wear gloves (recommendation: strong; evidence quality: high) and gowns (recommendation: strong; evidence quality: moderate) when entering rooms with CDI patients and when caring for them.

Voting:

A - 100\%; B - 0\%; C - 0\%; D - 0\%; E- 0\%

Acceptance level: HIGH.

Voting:

A - 83.3\%; B - 16.7\%; C - 0\%; D - 0\%; E- 0\%.

Acceptance level: HIGH.

\subsubsection{Discussion}

Preventive measures include gowns and gloves when caring for CDI patients. The hands of the hospital staff may be contaminated with $C$. difficile spores, especially when they do not wear gloves and are exposed to faeces [37]. In addition, when using gloves, remove them carefully so as not to contaminate your hands and forearms. It is recommended that protective gowns be worn due to the risk of contamination of uniforms. Contaminated uniforms can be a source of $C$. difficile transmission.

\subsection{Recommendation 13}

When should isolation be established?
Safety precautions should be established for pa-
tients suspected of CDI while waiting for the results
of $C$. difficile testing, when the results cannot be ob-
tained on the same day.
(Recommendation: strong; quality of evidence:
moderate)
Voting:
A- $83.3 \%$; $-16.3 \%$; $-0 \%$; D - $0 \%$; $-0 \%$.
Agreement level: HIGH.

\subsubsection{Discussion}

If there is a delay in test results, safety measures should be introduced similar to those for confirmed CDI. Patients with suspected CDI should be subjected to preventive safety measures while waiting for CDI confirmation [38].

\subsection{Recommendation 14}

\section{How long should the isolation last?}

Safety measures restricting contact with the patient should be continued up to at least $48 \mathrm{~h}$ after resolution of diarrhoea.

(Recommendation: weak; quality of evidence: low) Voting:

A - 50\%; B - 33.3\%; C - 16.7\%; D - 0\%; E - 0\%.

Agreement level: $\mathrm{HIGH}$.

It is appropriate to extend safety measures and restrict the contact with the patient until discharge if the $C D I$ incidence rate is high despite introduction of standard infection control measures.

(Recommendation: weak; quality of evidence: low) Voting:

A - 33.3\%; B - 50\%; C - 16.7\%; D - 0\%; E - 0\%.

Agreement level: $\mathrm{HIGH}$.

\subsubsection{Discussion}

According to British recommendations, safety measures should be continued up to $48 \mathrm{~h}$ after resolution of diarrhoea [39]. The average time to diarrhoea resolution is 4.2 days. There is no evidence for reduced CDI rate in response to prolongation of safety measures.

\subsection{Recommendation 15}

Which hand washing method is recommended (assuming glove use) during care for isolated CDI patients?

In the case of high CDI rates or an outbreak, routine hand washing with soap and water is the preferred method instead of alcohol-based products. Hand washing with soap and water before and after contact with CDI patients shows superior efficacy in removing $C$. difficile spores.

(Recommendations: strong; quality of evidence: moderate)

Voting:

A - 66.6\%; B - 16.7\%; C - 16.7\%; D - 0\%; E-0\%.

Agreement level: $\mathrm{HIGH}$.

Hand washing using water and soap is preferred when there is direct contact with faeces or probably contaminated skin region, e.g. perineal area.

(Good practice recommendation)

\section{Voting:}

A - 83.3\%; B - 16.7\%; C-0\%; D - 0\%; E-0\%.

Agreement level: $\mathrm{HIGH}$.

\subsubsection{Discussion}

The hands of the medical staff are often the source of $C$. difficile infection. A prospective study on 27 CDI 
patients showed that $C$. difficile can often contaminate various body regions including the groin, chest, abdomen, forearms, and hands. Contamination of chest or abdominal skin persisted after resolution of diarrhoea [40]. Patients with CDI symptoms are the main source of disease transmission. Their faeces contain a large number of spores, which are transferred/excreted to the environment. Contamination of skin, clothes, bedsheets, and surroundings have been appropriately called faecal veneer $[40,41]$. The hands of the medical personnel are an important vector of spore transmission onto vulnerable patients [41]. Patients may also become contaminated with spores due to direct contact with contaminated surfaces or appliances. If patient isolation in a single room with a separate bathroom is impossible, then hand washing is of upmost importance to prevent the disease transmission between patients, medical staff, and visitors [42]. It was proven that $C$. difficile can be isolated from hands and faeces of asymptomatic medical staff. Moreover, spores were also found in sewage, soil, and patients' houses. It is epidemiologically significant that C. difficile can survive for up to 5 months on the floor.

\subsection{Recommendation 16}

The role of the patient's bath in CDI prevention
Patients should be encouraged to wash their hands
and take a shower in order to decrease the amount
of $C$. difficile spores on the skin.
(Good practice recommendation)
Voting:
A- $100 \%$; $-0 \%$; $-0 \%$; D-0\%; E-0\%.
Agreement level: $\mathrm{HIGH}$.

\subsubsection{Discussion}

The patient can transport $C$. difficile spores on his or her contaminated hands. Hand washing and disinfection are important to prevent CDI recurrence. Patients should take a bath or shower regularly to decrease the number of spores on their skin [43].

\subsection{Recommendation 17}

Recommendations for cleaning non-critical equipment and accessories after their use by CDI patients Use disposable equipment if possible. Ensure that reusable equipment is thoroughly cleaned and disinfected, especially with use of sporicidal disinfectants compatible with the equipment.

(Recommendation: strong; quality of evidence: moderate)

Voting:

A - 83.3\%; B - 16.7\%; C - 0\%; D - 0\%; E - 0\%.

Agreement level: $\mathrm{HIGH}$.

\subsection{Recommendation 18}

The role of manual final disinfection using sporicidal disinfectants active against $C$. difficile in isolated CDI patients

Cleaning the rooms using sporicidal disinfectants should be considered in combination with other measures preventing $C D I$ endemic infections in the case of an epidemic or if there is evidence of recurring CDI in the same room.

(Recommendation: weak; quality of evidence: low) Voting:

A - 33.3\%; B - 66.7\%; C-0\%; D-0\%; E-0\%. Agreement level: HIGH.

\subsection{Recommendation 19}

\section{Assessment of cleaning effectiveness}

The goal of the quality of cleaning assurance is to define the rules of the cleaning effectiveness assessment.

Voting:

A - 100\%; B - 0\%; C - 0\%; D - 0\%; E - 0\%.

Agreement level: $\mathrm{HIGH}$.

\subsection{Recommendation 20}

The role of automatic terminal sporicidal disinfection against $C$. difficile in isolated CDI

Until now there have only been a few studies recommending the use of automatic terminal disinfection in CDI prevention.

(Non-recommended)

Voting:

A - 16.7\%; B - 66.6\%; C - 0\%; D - 0\%; E- $16.7 \%$.

Agreement level: $\mathrm{HIGH}$.

\subsubsection{Discussion}

There are technologies of contactless disinfection, for example ultraviolet light systems (UVL) or hydrogen peroxide vapours (HPV). Technology of contactless disinfection using ultraviolet light might be successful in the prevention of $C D I$ infections.

\subsection{Recommendation 21}

\section{The role of everyday sporicidal disinfection}

For CDI prevention, everyday cleaning using dedicated sporicidal disinfectants should be considered, especially in the case of an epidemic, pandemic, or recurrent cases of $\mathrm{CDI}$.

(Recommendation: weak; quality of evidence: low) Voting:

A - 16.7; B - 66.6\%; C - 16.7\%; D - 0\%; E - 0\%. Agreement level: HIGH. 


\subsubsection{Discussion}

Everyday cleaning using sporicidals decreases contamination with $C$. difficile. Available disinfectants include the following: hypochlorite-based solution (500 ppm of chlorine), quaternary ammonium compounds, whitening tissues with $0.55 \%$ active chlorine, and peracetic acid-based products $[1,44]$.

\subsection{Recommendation 22}

The necessity and usefulness of identification of asymptomatic carriers of $C$. difficile with further isolation of $C$. difficile carriers

There is a lack of evidence for compulsory screening of asymptomatic carriers for their isolation or implementation of safety measures.

(Not recommended)

Voting:

A - 50\%; B - 16.7\%; C - 0\%; D - 33.3\%; E- 0\%.

Agreement level: LOW.

\subsection{Recommendation 23}

The role of proper antibiotic therapy in control of CDI rate

In order to minimise the risk of CDI development, the frequency and duration of high-risk antibiotic therapy should be limited. Moreover, the number of prescribed antibiotics should be limited as well.

(Recommendation: strong; quality of evidence: moderate)

Voting:

A - 100\%; B - 0\%; C - 0\%; D-0\%; E- 0\%.

Agreement level: $\mathrm{HIGH}$.

The national program of rational antibiotic use should be implemented.

(Good practice recommendation)

Voting:

A - 100\%; B - 0\%; C - 0\%; D-0\%; E- 0\%.

Agreement level: $\mathrm{HIGH}$.

\subsubsection{Discussion}

In the case of a CDI epidemic it is important to implement supervision of the used antibiotics. The program of antibiotic rational use should be implemented. The frequency and duration of antibiotic therapy may have an impact on CDI development. The use of a considerable number of antibiotics (about four) is a significant risk factor of $C D I$ progression, while the number of $C$. difficile infections increases with the number of prescribed antibiotics [1]. CDI risk is associated with increased dosage, the number of antibiotics, and the duration of therapy. Adjusted hazard ratio (HR) of patients receiving two, three, four, or five antibiotics was, respectively, 2.5 (95\% Cl: 1.6-4.0), 3.3 (95\% Cl: 2.2-5.2), and 9.6 (95\% Cl: 6.1-15.1) times higher compared to patients with one drug. It is important to minimise the duration of drug administration and verify the validity of antibiotic therapy. Hospitals should implement antibiotic management programs. Benefits from these programs are as follows: improvement of the treatment results, decrease of adverse events such as CDI, and improvement of sensitivity to antibiotics $[45,46]$.

\subsection{Recommendation 24}

Decrease the frequency and duration of antibiotic therapy

In order to decrease the risk of CDI, the frequency and duration of high-risk antibiotic therapy and the number of prescribed antibiotics should be minimised.

(Recommendation: strong; quality of evidence: moderate)

Voting:

A - $100 \%$; B - 0\%; C-0\%; D - 0\%; E- 0\%.

Agreement level: $\mathrm{HIGH}$.

\subsubsection{Discussion}

Decrease of antibiotic use may be the best measure to limit the CDI infection rate in the case of an epidemic. Unnecessary antibiotic use should be avoided, and the duration of antibiotic therapy should be shortened.

\subsection{Recommendation 25}

\section{Targeted antibiotic therapy for CDI control}

The type of antibiotics used should reflect the local epidemiological situation and $C$. difficile strains. Reduced used of fluoroquinolones, clindamycin, and cephalosporins (except for surgical antibiotic prevention) should be taken into consideration.

(Recommendation: strong; quality of evidence: moderate)

\section{Voting:}

A - $100 \%$; B - 0\%; C - 0\%; D - 0\%; E - 0\%.

Agreement level: $\mathrm{HIGH}$.

\subsection{Recommendation 26}

The role of proton-pump inhibitors (PPI) use reduction in CDI prevention

There is an epidemiological association between PPI and CDI. If there are no definite indications for PPI therapy, it should be discontinued. There are insufficient data to indicate cessation of PPI therapy as a CDI prevention measure.

(Non-recommended)

Voting:

A - 83.3\%; B - 16.7\%; C-0\%; D-0\%; E-0\%.

Agreement level: $\mathrm{HIGH}$. 


\subsubsection{Discussion}

Many studies reported the associations between PPI and CDI $[47,48]$. Despite clinical data indicating a constantly increased risk of CDI in patients receiving $\mathrm{PPI}$ therapy, the impact of PPI on CDI incidence is still not clearly established. Many clinical trials were characterised by data heterogeneity, the influence of unidentified confounding factors, or lack of dose-dependent effect. Because of an unclear association between PPI therapy and CPI development, PPI therapy with no clear indications should be discontinued.

\subsection{Recommendation 27}

Usefulness of probiotics in primary CDI prevention At the moment there are insufficient data about the role of probiotics in primary CDI prevention, and thus no clear recommendation can be given.

\section{(Not recommended)}

Voting:

A - 50\%; B - 16.7\%; C - 16.7\%; D - 16.7\%; E - 0\%. Agreement level: LOW.

\subsubsection{Discussion}

The literature gives contradictory information about the influence of probiotics in C. difficile prevention.

Lactobacillus plantarum 299 v (Lp299v) colonises healthy individuals' digestive tract mucosa following oral administration. Its excellent adhering properties are a result of binding to mannose of the mucosal cells. This strain, due to its adherence, colonises rectal mucosa and is able to survive for up to 11 days after the supplementation is stopped, which prevents adherence of other pathogenic bacteria. Moreover, studies showed that $L p 299 \mathrm{~V}$ stimulates production of mucin by intestinal cells [49]. Lp299 is vulnerable to antibiotics such as ampicillin, erythromycin, and trimethoprim/sulfamethoxazole $[50,51]$. Studies including patients receiving antibiotic therapy supplemented by either $L p 299 \mathrm{~V}$ or genomically similar L. plantarum 299 showed high safety profile and lack of significant side effects [47, 52].

Saccharomyces boulardii is a probiotic that was shown to decrease the infection recurrence in patients with severe or recurring $\operatorname{CDI}[53,54]$. Studies on animal models showed that this probiotic causes an increase in antibodies against toxin A, which subsequently decreases the intensity of CDI symptoms. Moreover, S. boulardii has an anti-inflammatory effect due to suppression of the nuclear transcription factor $\kappa \mathrm{B}(\mathrm{NF}-\kappa \mathrm{B})$, and it reduces IL-8 production, which is a mediator of inflammatory response in CDI [55].

Products containing S. boulardii are available on the Polish market; some of them contain S. boulardii exclu- sively, others contain additional probiotics and prebiotics (e.g. inulin).

Clinical studies also assessed the efficacy of Lactobacillus acidophilus and Bifidobacterium bifidum in patients receiving antibiotics in CDI prevention. The proportion of CDI patients was higher in the group of patients receiving placebo compared to those on probiotic supplementation. On the other hand, patients receiving the probiotic were characterised by more frequent $C$. difficile colonisation without toxin presence in stool [56].

Probiotics may be useful in CDI prevention if they are administered (without previous history of CDI) during antibiotic therapy $[57,58]$. There have also been reports on infection caused by probiotic microorganisms [58]. Previous scientific reports showed limited success in $\mathrm{CDI}$ decrease in high-risk patients who received systemic antibiotics. Due to a lack of reliable studies and insufficient data, there are no recommendations for probiotic administration in CDI prevention [51].

\section{Treatment}

\subsection{Recommendation 28}

\section{Supportive treatment in CDI}

The antibiotic that triggered the infection should be discontinued as soon as possible because it may affect the risk of $C D I$ recurrence.

(Recommendation: strong; quality of evidence: moderate)

Voting:

$A-83.3 \%$; B - 16.7\%; C - 0\%; D - 0\%; E-0\%.

Acceptance level: HIGH.

Empirical CDI antibiotic therapy should be implemented when a significant delay in laboratory confirmation is expected or in the case of fulminant CDI. (Recommendation: weak; quality of evidence: low) Voting:

A - 33.3\%; B - 66.7\%; C-0\%; D - 0\%; E-0\%.

Acceptance level: $\mathrm{HIGH}$.

\subsubsection{Discussion}

Discussion is described in Recommendation 30. 


\subsection{Recommendation 29}

The safest and most effective treatment regimen for the first CDI episode

Treatment of the first CDI episode should have high efficacy and cause symptom relief and resolution within a month after the therapy. Vancomycin or fidaxomicin are the drugs of choice for the treatment of the first CDI episode. Vancomycin $125 \mathrm{mg}$ four times a day PO for 10 days or fidaxomicin $200 \mathrm{mg}$ twice daily for 10 days are recommended.

(Recommendation: strong; quality of evidence: high) Voting:

A - 100\%; B - 0\%; C - 0\%; D - 0\%; E-0\%.

Acceptance level: HIGH.

Metronidazole should only be used for the first episode of non-severe CDI, and only in the face of limited access to vancomycin and fidaxomicin. The metronidazole regimen is $500 \mathrm{mg}$ three times a day PO for 10 days.

(Recommendation: weak; quality of evidence: high) Voting:

A - 83.3\%; B - 16.7\%; C - 0\%; D - 0\%; E-0\%. Acceptance level: HIGH.

Due to potential neurotoxicity of metronidazole, treatment exceeding 10 days should be avoided.

(Recommendation: strong; quality of evidence: moderate)

Voting:

A - 100\%; B - 0\%; C - 0\%; D - 0\%; E-0\%.

Acceptance level: HIGH.

\subsubsection{Discussion}

Treatment of the first episode of CDI involves vancomycin orally at the dose of $125 \mathrm{mg}$ four times a day or fidaxomicin $200 \mathrm{mg}$ twice daily. The therapy should last for 10 days. If vancomycin or fidaxomicin is not available and the infection is mild, you can give met- ronidazole $500 \mathrm{mg}$ three times a day PO for 10 days. Prolonged metronidazole therapy can be dangerous because of its neurotoxic effect. Treatment regimens and comparison of treatment efficacy of the first episode are presented in Tables IX and X [10, 16, 59-64].

Table IX. Treatment of $C$. difficile infection in adults according to IDSA and SHEA guidelines [10]

\begin{tabular}{|c|c|c|}
\hline Type of infection & Additional information & Recommended treatment \\
\hline $\begin{array}{l}\text { First episode with } \\
\text { mild or moderate } \\
\text { course }\end{array}$ & $\begin{array}{l}\text { Leukocytosis } \leq 15,000 / \mathrm{ml} \\
\text { creatinine } \leq 1.5 \mathrm{mg} / \mathrm{dl}\end{array}$ & $\begin{array}{l}\text { Vancomycin } 125 \mathrm{mg} \text { PO four times a day for } 10 \text { days, or } \\
\text { fidaxomicin } 200 \mathrm{mg} \text { twice daily for } 10 \text { days; } \\
\text { when the above are unavailable: metronidazole } 500 \mathrm{mg} \text { PO three times } \\
\text { daily for } 10 \text { days }\end{array}$ \\
\hline $\begin{array}{l}\text { First episode with } \\
\text { severe course }\end{array}$ & $\begin{array}{l}\text { Leukocytosis }>15 \mathrm{000} / \mathrm{ml} \\
\text { creatinine } \geq 1.5 \mathrm{mg} / \mathrm{dl}\end{array}$ & $\begin{array}{l}\text { Vancomycin } 125 \text { mg PO four times a day for } 10 \text { days or } \\
\text { fidaxomicin } 200 \text { mg twice daily for } 10 \text { days }\end{array}$ \\
\hline $\begin{array}{l}\text { First episode with } \\
\text { fulminant course }\end{array}$ & Shock, ileus, toxic megacolon & $\begin{array}{c}\text { Vancomycin } 500 \text { mg four times a day PO or through a NG tube, if ileus - } \\
\text { consider adding vancomycin rectally } \\
\text { Metronidazole } 500 \text { mg IV every } 8 \text { h should be given together with } \\
\text { vancomycin, especially if ileus is present }\end{array}$ \\
\hline First relapse & & $\begin{array}{l}\text { If the first episode was treated with metronidazole: vancomycin } 125 \mathrm{mg} \text { PO } \\
\qquad \text { four times a day for } 10 \text { days; } \\
\text { if the first episode was treated with standard-dose vancomycin: } \\
\text { vancomycin - prolonged treatment with gradually reduced doses: } 125 \mathrm{mg} \\
\text { four times a day for } 10-14 \text { days, then twice daily for a week, then once } \\
\text { a day for a week, finally every } 2 \text { to } 3 \text { days for } 2 \text { to } 8 \text { weeks, } \\
\text { or } \\
\text { fidaxomicin } 200 \text { mg twice daily for } 10 \text { days }\end{array}$ \\
\hline $\begin{array}{l}\text { Second or } \\
\text { subsequent relapse }\end{array}$ & & $\begin{array}{c}\text { Vancomycin - prolonged treatment with gradually reduced doses as } \\
\text { described above, } \\
\text { or } \\
\text { vancomycin } 125 \text { mg four times a day for } 10 \text { days followed by rifaximin } \alpha \\
400 \mathrm{mg} \text { three times a day for } 20 \text { days, } \\
\text { or fidaxomicin } 200 \text { mg twice daily for } 10 \text { days, } \\
\text { or } \\
\text { faecal microbiota transplant }\end{array}$ \\
\hline
\end{tabular}


Table X. Efficacy comparison of various regimens/treatment option for $C$. difficile infection according to IDSA and SHEA guidelines [10]

\begin{tabular}{|c|c|c|c|c|c|c|}
\hline Evaluated outcome & $\begin{array}{c}\text { Number of } \\
\text { participants } \\
\text { (Number of studies) }\end{array}$ & $\begin{array}{c}\text { Patient } \\
\text { percentage }\end{array}$ & $\begin{array}{l}\text { Relative risk } \\
(95 \% \mathrm{Cl})\end{array}$ & $P$-value & $\begin{array}{l}\text { Quality of } \\
\text { evidence }\end{array}$ & $\begin{array}{l}\text { First author } \\
\text { [References] }\end{array}$ \\
\hline \multicolumn{7}{|c|}{ Direct comparison of metronidazole with vancomycin } \\
\hline \multirow[t]{3}{*}{$\begin{array}{l}\text { Resolution of diarrhoea after } \\
10 \text { days of treatment }\end{array}$} & $\begin{array}{l}\text { RCT before 2000: } \\
156(2)\end{array}$ & $\begin{array}{l}95 \text { (MTR) } \\
98 \text { (VAN) }\end{array}$ & $\begin{array}{c}\text { RR: } 0.97 \\
(0.91-1.03)\end{array}$ & 0.4 & & $\begin{array}{c}\text { Teasley [59] } \\
\text { Wenisch [60] }\end{array}$ \\
\hline & $\begin{array}{l}\text { RCT before 2000: } \\
687 \text { (3) }\end{array}$ & $\begin{array}{l}75 \text { (MTR) } \\
85 \text { (VAN) }\end{array}$ & $\begin{array}{c}\text { RR: } 0.89 \\
(0.82-0.96)\end{array}$ & 0.002 & & $\begin{array}{c}\operatorname{Zar}[11] \\
\text { Johnson [61] }\end{array}$ \\
\hline & $\begin{array}{l}\text { Overall RCT: } \\
\quad 843(5)\end{array}$ & $\begin{array}{l}78 \text { (MTR) } \\
87 \text { (VAN) }\end{array}$ & $\begin{array}{c}\text { RR: } 0.89 \\
(0.85-0.96)\end{array}$ & 0.0008 & High & \\
\hline \multirow{3}{*}{$\begin{array}{l}\text { Resolution of diarrhoea after } \\
\text { treatment without CDI relapse } \\
\text { within a month }\end{array}$} & $\begin{array}{l}\text { RCT before 2000: } \\
156(2)\end{array}$ & $\begin{array}{l}85 \text { (MTR) } \\
84 \text { (VAN) }\end{array}$ & $\begin{array}{l}\text { RR: } 1.0 \\
(0.9-1.2)\end{array}$ & 1.0 & & $\begin{array}{l}\text { Teasley [59] } \\
\text { Wenisch [60] }\end{array}$ \\
\hline & $\begin{array}{l}\text { RCT after 2000: } \\
687(3)\end{array}$ & $\begin{array}{l}59(\text { MTR }) \\
70 \text { (VAN) }\end{array}$ & $\begin{array}{c}\text { RR: } 0.84 \\
(0.74-0.94)\end{array}$ & 0.002 & & $\begin{array}{c}\operatorname{Zar}[11] \\
\text { Johnson [61] }\end{array}$ \\
\hline & $\begin{array}{l}\text { Overall RCT: } \\
843(5)\end{array}$ & $\begin{array}{l}63 \text { (MTR) } \\
73 \text { (VAN) }\end{array}$ & $\begin{array}{c}\text { RR: } 0.87 \\
(0.79-0.96)\end{array}$ & 0.003 & High & \\
\hline \multicolumn{7}{|c|}{ Direct comparison of vancomycin and fidaxomicin } \\
\hline $\begin{array}{l}\text { Resolution of diarrhoea after } \\
10 \text { days of treatment }\end{array}$ & $1105(2)$ & $\begin{array}{l}88(\text { FDX) } \\
86(\text { VAN) }\end{array}$ & $\begin{array}{l}\text { RR: } 1.0 \\
(0.98-1.1)\end{array}$ & 0.36 & High & $\begin{array}{c}\text { Louie [62] } \\
\text { Cornely [63] }\end{array}$ \\
\hline $\begin{array}{l}\text { Resolution of diarrhoea after } \\
\text { treatment without CDI relapse } \\
\text { within a month }\end{array}$ & $1105(2)$ & $\begin{array}{l}71 \text { (FDX) } \\
57(\text { VAN) }\end{array}$ & $\begin{array}{c}\text { RR: } 1.2 \\
(1.1-1.4)\end{array}$ & $<0.0001$ & High & $\begin{array}{c}\text { Louie }[62] \\
\text { Cornely [63] }\end{array}$ \\
\hline \multicolumn{7}{|c|}{ Direct comparison of faecal transplant and vancomycin } \\
\hline $\begin{array}{l}\text { Resolution of diarrhoea after } \\
\text { treatment without CDI relapse } \\
\text { by } 56 \text { days after treatment }\end{array}$ & $29(1)$ & $\begin{array}{l}81 \text { (FMT) } \\
31 \text { (VAN) }\end{array}$ & $\begin{array}{l}\mathrm{RR}: 2.6 \\
(1.1-6.2)\end{array}$ & 0.01 & Moderate & van Nood [64] \\
\hline
\end{tabular}

\subsection{Recommendation 30}

\section{The best management of fulminant CDI}

Fulminant CDI is defined as a severe, complicated disease characterised by hypotension or shock, ileus, or acute toxic megacolon. Vancomycin PO is the treatment of choice for fulminant CDI. The vancomycin dosage is $500 \mathrm{mg}$ PO four times a day.

(Recommendation: strong; quality of evidence: moderate)

Voting:

A - 100\%; B - 0\%; C - 0\%; D - 0\%; E - 0\%.

Acceptance level: HIGH.

When CDI is complicated by ileus, vancomycin can be administered rectally. The dose of vancomycin is $500 \mathrm{mg}$ in $100 \mathrm{ml}$ saline every $6 \mathrm{~h}$ as a retention enema.

(Recommendation: weak; quality of evidence: low) Voting:

$A-83.3 \%$; $B-16.7 \%$; $-0 \%$; D - 0\%; E - 0\%.

Acceptance level: HIGH.
Metronidazole should be administered intravenously together with oral or rectal vancomycin, especially if there is intestinal obstruction. The metronidazole dose is $500 \mathrm{mg}$ IV every $8 \mathrm{~h}$.

(Recommendation: strong; quality of evidence: moderate)

Voting:

A-83.3\%; B - 0\%; C- 16.7\%; D - 0\%; E-0\%. Acceptance level: HIGH.

\subsubsection{Discussion}

Fulminant infection complicated by toxic megacolon, ileus, or shock should be treated with vancomycin $500 \mathrm{mg}$ PO four times daily. If intestinal obstruction is present, vancomycin can be administered rectally at the dose of $500 \mathrm{mg}$ in $100 \mathrm{ml} 0.9 \% \mathrm{NaCl}$ every $6 \mathrm{~h}$. Vancomycin therapy should be enhanced by intravenous metronidazole $500 \mathrm{mg}$ three times daily. 


\subsection{Recommendation 31}

\section{Surgical treatment for CDI}

We recommend surgical treatment for critically ill patients. The preferred method is subtotal rectal-sparing colectomy.

(Recommendation: strong; quality of evidence: moderate)

Voting:

$A-66.7 \% ; B-33.3 \% ; C-0 \% ; D-0 \% ; E-0 \%$.

Acceptance level: HIGH.

Loop ileostomy with colonic lavage followed by vancomycin lavage is an alternative approach that may lead to better treatment outcomes.

(Recommendation: weak; quality of evidence: low) Voting:

A - 50\%; B - 33.3\%; C - 16.7\%; D - 0\%; E - 0\%.

Acceptance level: $\mathrm{HIGH}$.

\subsubsection{Discussion}

If medical treatment proves ineffective, surgical treatment should be considered, including subtotal rectal-sparing colectomy [65].

\subsection{Recommendation 32}

The most effective and safe treatment regimen for the first $C D I$ recurrence

For the first CDI relapse, prolonged oral vancomycin therapy is recommended with a gradually reduced and pulsatile regimen instead of a second 10-day vancomycin cycle. The dose is $125 \mathrm{mg}$ four times a day for 10-14 days, later reduced to two times a day for a week, then once a day for a week, and finally once every two or three days for 2 to 8 weeks.

(Recommendation: weak; quality of evidence: low) Voting:

A-83.3\%; B - 0\%; C- 16.7\%; D-0\%; E-0\%.

Acceptance level: HIGH.

Alternatively, the first CDI relapse can be treated with fidaxomicin for 10 days instead of the standard 10 day vancomycin regimen if vancomycin was used in the initial therapy.

(Recommendation: weak; quality of evidence: moderate)

Voting:

$A-83.3 \%$; $B-0 \%$; C - 16.7\%; D - 0\%; E-0\%.

Acceptance level: HIGH.

Vancomycin in the standard 10-day regimen should be given when metronidazole was used for treatment of the first episode of CDI. Metronidazole treatment should not be repeated.
(Recommendation: weak; quality of evidence: low) Voting:

A - 83.3\%; B - 0\%; C - $16.7 \%$; D - 0\%; E - 0\%.

Acceptance level: HIGH.

\subsection{Recommendation 33}

The most effective and safe treatment regimen of the second or subsequent CDI recurrence

Patients with a second or subsequent CDI relapse should be treated with oral vancomycin in a pulsatile regimen. The dose of vancomycin is $125 \mathrm{mg} P O$ four times a day for 10-14 days, two times a day for a week, once a day for a week, then once every two or three days for 2 to 8 weeks.

(Recommendation: weak; quality of evidence: low) Voting:

A - 83.3\%; B - 0\%; C - 16.7\%; D - 0\%; E - 0\%.

Acceptance level: $\mathrm{HIGH}$.

OR

Patients with a second or subsequent CDI relapse should be treated with the standard vancomycin oral regimen, i.e. $125 \mathrm{mg}$ four times daily followed by $400 \mathrm{mg}$ rifaximin $\mathrm{PO}$ three times daily for 20 days.

(Recommendation: weak; quality of evidence: low) Voting:

$A-50 \%$; $B-33.3 \%$; $C-16.7 \%$; D - 0\%; E-0\%.

Acceptance level: HIGH.

Alternatively, patients with a second or subsequent relapse of $C D I$ may be treated orally with fidaxomicin $200 \mathrm{mg}$ twice daily for 10 days.

(Recommendation: weak; quality of evidence: low) Voting:

A - 66.6\%; B - 16.7\%; C - 16.7\%; D - 0\%; E - 0\%.

Acceptance level: HIGH.

\subsubsection{Discussion}

For treatment of CDI relapses, prolonged use of vancomycin in gradually reduced doses is recommended. The preferred regimen is $125 \mathrm{mg}$ four times a day for 10-14 days, then $125 \mathrm{mg}$ twice daily, then $125 \mathrm{mg}$ once a day, and $125 \mathrm{mg}$ every 2 to 3 days for 2 to 8 weeks. It is also justified to treat relapses with fidaxomicin $200 \mathrm{mg}$ twice daily for 10 days instead of vancomycin. The vancomycin standard 10-day regimen should be used if the first episode was treated with metronidazole [1].

Subsequent relapses (second or later) require prolonged vancomycin or fidaxomicin course. Vancomycin $125 \mathrm{mg}$ four times a day for 10-14 days, then twice a day for 7 days, then once a day for 7 days, then once a day every 2 to 3 days for a period of 2 to 8 weeks. It 
is also possible to prescribe rifaximin $\alpha 400 \mathrm{mg}$ three times a day for 20 days after a standard 10-day vancomycin course. Fidaxomicin is recommended for a relapse at a dose of $200 \mathrm{mg}$ twice a day for 10 days.

Rifaximin atherapy is new and was first introduced in the guidelines for CDI treatment in 2018. In the study by Garey et al. in 2011, it was shown that the use of rifaximin reduced the $\mathrm{CDI}$ recurrence significantly more often [66]. Treatment regimens and comparison of treatment efficacy for the first episode are presented in Tables IX and X.

\subsection{Recommendation 34}

\section{Faecal microbiota transplant for CDI treatment}

Faecal microbiota transplant is recommended for CDI treatment in patients with multiple recurrences, in whom targeted antibiotic therapy proved ineffective.

(Recommendation: strong; quality of evidence: moderate)

Voting:

A - 50\%; B - 50\%; C-0\%; D-0\%; E-0\%.

Acceptance level: HIGH.

\subsubsection{Discussion}

Antibiotic therapy used in CDI patients is associated with the risk of relapse. Some patients experience multiple relapses. Promising treatment outcomes in those cases have been obtained following faecal microbiota transplant (FMT). FMT involves administration of faecal filtrate obtained from a healthy donor to the patient's intestines, with the aim of curing CDI and restoring the missing components of the intestinal microbiota. The effect can be observed after administration of one or two doses through a colonoscope or by rectal infusion. Curative factors in FMT therapy include not only live bacteria, but also bacterial components, antimicrobial compounds of bacterial origin, e.g. bacteriocins or bacteriophages, which contribute to normalisation of intestinal microbiota after CDI. FMT can be administered by rectal enema, through an NG tube, or in the form of freeze-dried capsules. The capsules can potentially become popular due to their low invasiveness and simple administration. Patients undergoing FMT achieve remission of the CDI-related diarrhoea, which is not always the result of reinfection but can stem from post-infectious irritable bowel syndrome. Such postinfectious diarrhoea is associated with other microbiota abnormalities. The use of FMT can be extended to dysbiosis caused by other bacteria responsible for enteritis [67].

The effectiveness of FMT is still subject to research, and the effectiveness of FMT was lower in magnitude in randomised controlled trials compared to non-ran- domised studies $[68,69]$. Because the use of FMT is still new, the long-term effects of FMT therapy are not yet known.

FMT is an effective treatment option in infections caused by the highly virulent $027 \mathrm{C}$. difficile ribotype, which is also highly resistant to antibiotics. The treatment consists of vancomycin for four days at the dose of $4 \times 125 \mathrm{mg}$ PO followed by FMT [70].

Donor preparation for FMT involves taking thorough medical history, obtaining blood samples, testing for hepatitis A, B, and C viruses, and HIV infection. Collected faecal samples are examined for the presence of parasites, toxins $A$ and $B$ of $C$. difficile, Helicobacter pylori antigen, and bacteria including Salmonella, Shigella, Campylobacter, Escherichia coli 0157:H7, as well as Yersinia enterocolitica. In addition, the tests for cytomegalovirus, Epstein-Barr virus, and rotaviruses are carried out [71].

Quraishi et al. in their meta-analysis of 37 studies, including seven randomised controlled studies, showed that FMT was more effective than vancomycin treatment $(R R=0.23,95 \% \mathrm{Cl}: 0.07-0.80)$ for relapsing and refractory CDI. The clinical effect in all studies was 92\% (95\% Cl: 89-94\%). Significantly higher efficacy was observed if FMT was performed in the lower gastrointestinal tract compared to the upper segment - 95\% (95\% Cl: $92-97 \%)$ vs. 88\% (95\% Cl: 82-94\%), $p=0.02$. There were no differences between fresh and frozen FMT 92\% (95\% Cl: 89-95\%) vs. 93\% (95\% Cl: 87-97\%), respectively, $p=0.84$. Subsequent administration of FMT cycles after failure of the first FMT resulted in a further increase in treatment efficacy. Donor testing was consistent, but there was variability in recipient preparation and FMT volume. The above analysis proves that FMT, regardless of the route of administration, is an effective treatment for recurrent and refractory CDI [72].

Similarly, in Poland Grzesiowski et al. [73] obtained the curative rate of $55 / 62$ (88.7\%) in recurrent CDI ( $\mathrm{rCDI}$ ); $76.5 \%$ of cures occurred after the first course of treatment, $14.5 \%$ after the second, and the remaining $9 \%$ after the third infusion through the nasogastric tube. The results by Grzesiowski are particularly important because they indicate that in most cases CDI treatment should be planned with implementation of FMT cycles (not just a single transplant), bringing the expected curative rate to nearly $100 \%$.

Research on faecal filtrate transfer (FFT) is underway. FFT is a clear brown liquid with no intense odour. Preparation of FFT consists of filtering faecal suspension through air pressure filtration systems; however, such filtrate has a reduced microbiota composition compared to FMT [67]. 


\subsection{Recommendation 35}

Treatment of patients requiring continuation of targeted antibiotic therapy against primary infection or repeated antibiotic therapy shortly after finishing CDI treatment

There are currently insufficient data on patients requiring continuous antibiotic therapy for the primary infection or requiring repeated antibiotic therapy shortly after discontinuing CDI treatment to recommend prolongation of treatment against $C$. difficile, or treatment using non-standard therapy, or resuming $C$. difficile treatment.

\section{(Not recommended)}

Voting:

A - 33.3\%; B - 50\%; C - 16.7\%; D - 0\%; E - 0\%.

Acceptance level: HIGH.

\subsubsection{Discussion}

A new form of CDI treatment is the administration of bezlotoxumab. It is a human monoclonal antibody that binds to $C$. difficile toxin $B$, neutralises it, and prevents damage to the cells of the colonic mucosa. To date, too few studies have been conducted to confirm its effectiveness, and phase III trials are ongoing [74]. According to the data from the summary of product characteristics, the drug should be administered during antibiotic therapy for CDI [75]. The novel mechanism of action of the drug does not directly affect the colon microbiome, and bezlotoxumab therapy may be an alternative treatment for recurrent $C$. difficile infection in patients at risk [76].

Research on $C$. difficile vaccine are still ongoing. Active vaccination may be, in the future, a form of CDI prevention. There are currently three products in the clinical phase trials [77]. In addition, they are also being studied with biotherapeutics, i.e. products containing toxin-non-forming $C$. difficile strains. There is also an oral $\beta$-lactamase (SYN-004) being studied that is supposed to protect the colonic microbiota by reducing the antibiotic concentration in the intestinal lumen. SYN-004 - ribaxamase is an oral $\beta$-lactamase that has been designed for administration together with intravenous $\beta$-lactam antibiotics [78].

\section{Conflict of interest}

The authors declare no conflict of interest.

\section{References}

1. McDonald LC, Gerding DN, Johnson S, et al. Clinical Practice Guidelines for Clostridium difficile Infection in Adults and Children: 2017 Update by the Infectious Diseases Society of America (IDSA) and Society for Healthcare Epidemiology of America (SHEA). Clin Infect Dis 2018; 66: e1-48.
2. Depestel DD, Aronoff DM. Epidemiology of Clostridium difficile infection. J Pharm Pract 2013; 26: 462-75.

3. https://www.ecdc.europa.eu/en/publications-data/healthcareassociated-infections-clostridium-difficile-infections-annual

4. Rydzewska G. Farmakoterapia zakażeń Clostridium difficile. Forum Zakażeń 2015; 6: 311-7.

5. Martirosian G, Hryniewicz W, Ozorowski T, et al. Zakażenia Clostridioides (Clostridium) difficile: epidemiologia, diagnostyka, terapia, profilaktyka. Narodowy Instytut Leków 2018; 1-30.

6. Pituch H, Obuch-Woszczatyński P, Lachowicz D, et al. Hospital-based Clostridium difficile infection surveillance reveals high proportions of PCR ribotypes 027 and 176 in different areas of Poland, 2011 to 2013. Eurosurveillance 2015; 20: pii=30025. https://doi.org/10.2807/1560-7917. ES.2015.20.38.30025.

7. Sadkowska-Todys M, Zieliński A, Czarkowski MP. Choroby zakaźne w Polsce w 2015 roku. Przegl Epidemiol 2017; 71: 295-309.

8. http://wwwold.pzh.gov.pl/oldpage/epimeld/2017/Ch_2017_ wstepne_dane.pdf

9. Kyne L, Warny M, Qamar A, Kelly CP. Asymptomatic carriage of Clostridium difficile and serum levels of IgG antibody against Toxin A. N Engl J Med 2002; 342: 390-7.

10. McDonald LC, Gerding DN, Johnson S, et al. Clinical Practice Guidelines for Clostridium difficile Infection in Adults and Children: 2017 Update by the Infectious Diseases Society of America (IDSA) and Society for Healthcare Epidemiology of America (SHEA). Clin Infect Dis 2018; 66: e1-48.

11. Zar FA, Bakkanagari SR, Moorthi KM, Davis MB. A comparison of vancomycin and metronidazole for the treatment of Clostridium difficile - associated diarrhea, stratified by disease severity. Clin Infect Dis 2007; 45: 302-7.

12. MCDonald LC, Coignard B, Dubberke E, et al. Recommendations for surveillance of Clostridium difficile - associated disease. Infect Control Hosp Epidemiol 2007; 28: 140-5.

13. Navaneethan U, Venkatesh PG, Shen B. Clostridium infection and inflammatory bowel disease: understanding the evolving relationship. World J Gastroenterol 2010; 16: 4892-904.

14. Dubberke E, Deborah S, Mayer J, Stevenson K. Implementing Automated surveillance for tracking Clostridium difficile infection at multiple healthcare facilites. Infect Control Hosp Epidemiol 2012; 33: 305-8.

15. Tedesco FJ, Barton RW, Alpers DH. Clindamycin-associated colitis: a prospective study. Ann Intern Med 1974; 81: 429-33.

16. Johnson S, Louie TJ, Gerding DN, et al. Vancomycin, metronidazole, or tolevamer for Clostridium difficile infection: results from two multinational, randomized, controlled trials. Clin Infect Dis 2014; 59: 345-54.

17. Albrecht P, Pituch $\mathrm{H}$. Clostridium difficile - narastający problem diagnostyczny i terapeutyczny. Onkol Prakt Klin 2013; 9: 22-31.

18. Jones BL, Wiuff C, Coia JE. UK laboratory diagnosis of Clostridium difficile infection: in a state of transition, confusion, or both? J Hosp Infect 2012; 81: 216.

19. Eastwood K, Else P, Charlett A, Wilcox M. Comparison of nine commercially available Clostridium difficile toxin detection assays, a real-time PCR assay for $C$. difficile tcdB, and a glutamate dehydrogenase detection assay to cytotoxin testing 
and cytotoxigenic culture methods. J Clin Microbiol 2009; 47: 3211-7.

20. Planche T, Aghaizu A, Holliman R, et al. Diagnosis of Clostridium difficile infection by toxin detection kits: a systematic review. Lancet Infect Dis 2008; 8: 777-84.

21. Dubberke ER, Han Z, Bobo L, et al. Impact of clinical symptoms on interpretation of diagnostic assays for Clostridium difficile infections. J Clin Microbiol 2011; 49: 2887-93.

22. Kaltsas A, Simon M, Unruh LH, et al. Clinical and laboratory characteristics of Clostridium difficile infection in patients with discordant diagnostic test results. J Clin Microbiol 2012; 50: 1303-7.

23. Humphries RM, Uslan DZ, Rubin Z. Performance of clostridium difficile toxin enzyme immunoassay and nucleic acid amplification tests stratified by patient disease severity. J Clin Microbiol 2013; 51: 869-73.

24. Longtin Y, Trottier S, Brochu G, et al. Impact of the type of diagnostic assay on clostridium difficile infection and complication rates in a mandatory reporting program. Clin Infect Dis 2013; 56: 67-73.

25. Planche TD, Davies KA, Coen PG, et al. Differences in outcome according to Clostridium difficile testing method: a prospective multicentre diagnostic validation study of $\mathrm{C}$. difficile infection. Lancet Infect Dis 2013; 3099: 70200-7.

26. Polage CR, Gyorke CE, Kennedy MA, et al. Overdiagnosis of Clostridium difficile infection in the molecular test Era. JAMA Intern Med 2015; 175: 1792-801.

27. Peterson LR, Manson RU, Paule SM, et al. Detection of toxigenic clostridium difficile in stool samples by real-time polymerase chain reaction for the diagnosis of $C$. difficile-associated diarrhea. Clin Infect Dis 2007; 45: 1152-60.

28. Sherwood RA. Faecal markers of gastrointestinal inflammation. J Clin Pathol 2012; 65: 981-5.

29. Cutone A, Lepanto MS, Rosa L, et al. Aerosolized bovine lactoferrin counteracts infection, inflammation and iron dysbalance in a cystic fibrosis mouse model of pseudomonas aeruginosa chronic lung infection. Int J Mol Sci 2019; 20: 2128.

30. Eder P. Przydatność biomarkerów w ocenie aktywności nieswoistych chorób zapalnych jelit - wskazówki praktyczne. Gastroenterol Klin 2018; 10: 52-63.

31. Adamek K. Metody diagnostyki funkcji bariery jelitowej. Przegl Lek 2017; 393-8.

32. El Feghaly RE, Stauber JL, Deych E, et al. Markers of intestinal inflammation, not bacterial burden, correlate with clinical outcomes in Clostridium difficile infection. Clin Infect Dis 2013; 56: $1713-21$

33. Muto CA, Blank MK, Marsh JW, et al. Control of an outbreak of infection with the hypervirulent Clostridium difficile BI strain in a university hospital using a comprehensive 'bundle' approach. Clin Infect Dis 2007; 45: 1266-73.

34. Yakob L, Riley TV, Paterson DL, et al. Assessing control bundles for Clostridium difficile: a review and mathematical model. Emerg Microbes Infect 2014; 3: e43.

35. Evans ME, Kralovic SM, Simbartl LA, et al. Effect of a Clostridium difficile infection prevention initiative in veterans affairs acute care facilities. Infect Control Hosp Epidemiol 2016; 37 $720-2$
36. Teltsch DY, Hanley J, Loo V, et al. Infection acquisition following intensive care unit room privatization infection after ICU room privatization. JAMA Intern Med 2011; 171: 32-8.

37. McFarland LV, Mulligan ME, Kwok RY, Stamm WE. Nosocomial acquisition of Clostridium difficile infection. N Engl J Med 1989; 320: 204-10.

38. Sunkesula VCK, Kundrapu S, Jury LA, et al. Potential for transmission of spores by patients awaiting laboratory testing to confirm suspected Clostridium difficile infection. Infect Control Hosp Epidemiol 2013; 34: 306-8.

39. Department of Health Protection Agency. Clostridium difficile infection: how to deal with the problem. 2008; 1-140.

40. Bobulsky GS, Al-Nassir WN, Riggs MM, et al. Clostridium difficile skin contamination in patients with $\mathrm{C}$. difficile-associated disease. Clin Infect Dis 2008; 46: 447-50.

41. Riggs MM, Sethi AK, Zabarsky TF, et al. Asymptomatic carriers are a potential source for transmission of epidemic and nonepidemic Clostridium difficile strains among long-term care facility residents. Clin Infect Dis 2007; 45: 992-8.

42. Ragusa R, Giorgianni G, Lupo L, et al. Healthcare-associated Clostridium difficile infection: role of correct hand hygiene in cross-infection control. J Prev Med Hyg 2018; 59: E145-52.

43. Dancer SJ. Controlling hospital-acquired infection: focus on the role of the environment and new technologies for decontamination. Clin Microbiol Rev 2014; 27: 665-90.

44. Kundrapu S, Sunkesula V, Jury LA, et al. Daily disinfection of high-touch surfaces in isolation rooms to reduce contamination of healthcare workers' hands. Infect Control Hosp Epidemiol 2012; 33: 1039-42.

45. Stevens V, Dumyati G, Fine LS, et al. Cumulative antibiotic exposures over time and the risk of Clostridium difficile infection. Clin Infect Dis 2011; 53: 42-8.

46. Barlam TF, Cosgrove SE, Abbo LM, et al. Executive summary: implementing an antibiotic stewardship program: guidelines by the Infectious Diseases Society of America and the Society for Healthcare Epidemiology of America. Clin Infect Dis 2016; 62: 1197-202.

47. Tleyjeh M, Bin Abdulhak AA, Riaz M, et al. Association between proton pump inhibitor therapy and Clostridium difficile infection: a contemporary systematic review and meta-analysis. PLoS One 2012; 7: e50836.

48. Garey W, Sethi S, Yadav Y, DuPont HL. Meta-analysis to assess risk factors for recurrent Clostridium difficile infection. J Hosp Infect 2008; 70: 298-304.

49. Mack DR, Ahrne S, Hyde L, et al.Extracellular MUC3 mucin secretion follows adherence of Lactobacillus strains to intestinal epithelial cells in vitro. Gut 2003; 52: 827-33.

50. Klarin B, Johansson M, Molin G, et al. Adhesion of the probiotic bacterium Lactobacillus plantarum 299v onto the gut mucosa in critically ill patients: a randomised open trial. Crit Care 2005; 9: R285-93.

51. Mack DR, Michail S, Wei S, et al. Probiotics inhibit enteropathogenic E. coli adherence in vitro by inducing intestinal mucin gene expression. Am J Physiol Gastrointest Liver Physiol 1999; 276: 4.

52. Klarin B, Wullt M, Palmquist I, et al. Lactobacillus plantarum $299 v$ reduces colonisation of Clostridium difficile in critically ill patients treated with antibiotics. Acta Anaesthesiol Scand 2008; 52: 1096-102. 
53. Dendukuri N, Costa V, McGregor M, Brophy JM. Probiotic therapy for the prevention and treatment of Clostridium difficile-associated diarrhea: a systematic review. CMAJ 2005; 173: $167-70$.

54. Meglicka M, Kierkuś J. Rola probiotyków w nawracających zakażeniach Clostridium difficile u dzieci. Forum Zakażeń 2015; 6: 29-36.

55. Sougioultzis S, Simeonidis S, Bhaskar KR, et al. Saccharomyces boulardii produces a soluble anti-inflammatory factor that inhibits NF-kappaB-mediated IL-8 gene expression. Biochem Biophys Res Commun 2006; 343: 69-76.

56. Plummer S, Weaver MA, Harris JC, et al. Clostridium difficile pilot study: effects of probiotic supplementation on the incidence of C. difficile diarrhoea. Int Microbiol 2004; 7: 59-62.

57. Pattani R, Palda VA, Hwang SW, Shah PS. Probiotics for the prevention of antibiotic-associated diarrhea and Clostridium difficile infection among hospitalized patients: systematic review and meta-analysis. Open Med 2013; 7: e56-67.

58. Johnson S, Maziade PJ, McFarland LV, et al. Is primary prevention of Clostridium difficile infection possible with specific probiotics? Int J Infect Dis 2012; 16: e786-92.

59. Teasley D, Gerding DN, Olson MM, et al. Prospective randomised trial of metronidazole versus vancomycin for Clostridium-difficile-associated diarrhoea and colitis. Lancet 1983 2: $1043-6$

60. Wenisch C, Parschalk B, Hasenhundl M, et al. Comparison of vancomycin, teicoplanin, metronidazole, and fusidic acid for the treatment of Clostridium difficile-associated diarrhea. Clin Infect Dis 1996; 22: 813-8.

61. Johnson S, Louie TJ, Gerding DN, et al. Vancomycin, metronidazole, or tolevamer for Clostridium difficile infection: results from two multinational, randomized, controlled trials. Clin Infect Dis 2014; 59: 345-54.

62. Louie TJ, Miller MA, Mullane KM, et al. Fidaxomicin versus vancomycin for Clostridium difficile infection. N Engl J Med 2011; 364: 422-31.

63. Cornely OA, Crook DW, Esposito R, et al. Fidaxomicin versus vancomycin for infection with Clostridium difficile in Europe, Canada, and the USA: a double-blind, non-inferiority, randomised controlled trial. Lancet Infect Dis 2012; 12: 281-9.

64. van Nood E, Vrieze A, Nieuwdorp M, et al. Duodenal infusion of donor feces for recurrent Clostridium difficile. N Engl J Med 2013; 368: 407-15.

65. Sartelli M, Di Bella S, McFarland LV, et al. 2019 update of the WSES guidelines for management of Clostridioides (Clostridium) difficile infection in surgical patients. World J Emerg Surg 2019; 14: 8.

66. Garey W, Ghantoji SS, Shah DN, et al. A randomized, double-blind, placebo-controlled pilot study to assess the ability of rifaximin to prevent recurrent diarrhoea in patients with Clostridium difficile infection. J Antimicrob Chemother 2011; 66: 2850-5.

67. Ott SJ, Waetzig GH, Rehman A, et al. With Clostridium difficile infection. Gastroenterology 2017; 152: 799-811e7.

68. Cammarota G, Masucci L, laniro G, et al. Randomised clinical trial: faecal microbiota transplantation by colonoscopy vs. vancomycin for the treatment of recurrent Clostridium difficile infection. Aliment Pharmacol Ther 2015; 41: 835-43.
69. Youngster I, Sauk J, Pindar C, et al. Fecal microbiota transplant for relapsing Clostridium difficile infection using a frozen inoculum from unrelated donors: a randomized, open-label, controlled pilot study. Clin Infect Dis 2014; 58: 1515-22.

70. Di S, Gouliouris T, Petrosillo N. Fecal microbiota transplantation (FMT) for Clostridium difficile infection: focus on immunocompromised patients. J Infect Chemother 2015; 21: 230-7.

71. Juszczuk K, Grudlewska K, Mikucka A, Gospodarek-Komkowska E. Przeszczepienie mikrobioty jelitowej - metoda leczenia nawracających zakażeń o etiologii Clostridium difficile i innych chorób.. Postepy Hig Med Dosw 2017; 71: 220-6.

72. Quraishi MN, Widlak M, Bhala N, et al. Systematic review with meta-analysis: the efficacy of faecal microbiota transplantation for the treatment of recurrent and refractory Clostridium difficile infection. Aliment Pharmacol Ther 2017; 46: 479-93.

73. Grzesiowski P, Hermann A, Dubaniewicz A, et al. Effectiveness of FMT in recurrent Clostridium difficile infection. Antimicrob Resist Infect Control 2015; 4 Suppl 1: P27.

74. Wilcox MH, Gerding DN, Poxton IR, et al. Bezlotoxumab for prevention of recurrent Clostridium difficile infection. $\mathrm{N}$ Engl J Med 2017; 376: 305-17.

75. Charakterystyka produktu leczniczego ZINPLAVA $25 \mathrm{mg} / \mathrm{ml}$. European Medicines Agency.

76. Alonso CD, Mahoney MV. Bezlotoxumab for the prevention of Clostridium difficile infection: a review of current evidence and safety profile. Infect Drug Resist 2018; 12: 1-9.

77. Leuzzi R, Adamo R, Scarselli M. Vaccines against Clostridium difficile. Hum Vaccin Immunother 2014; 10: 1466-77.

78. Kokai-Kun F, Roberts T, Coughlin O, et al. Use of ribaxamase (SYN-004), a beta-lactamase, to prevent Clostridium difficile infection in beta-lactam-treated patients: a double-blind, phase $2 b$, randomised placebo-controlled trial. Lancet Infect Dis 2019; 19: 487-96.

Received: 3.02 .2020

Accepted: 17.02 .2020 